\title{
Recent Developments in Search of Effective Herbal Medicine for The Treatment of Leukemia
}

\author{
Gagandeep Singh Shergill*, Suvechha Bhandari and Terry L Oroszi \\ Department of Pharmacology \& Toxicology, Boonshoft School of Medicine, Wright State University, USA
}

\begin{abstract}
*Corresponding author: Gangandeep Singh Shergill, Department of Pharmacology \& Toxicology, Boonshoft School of Medicine, Wright State University, 3640 Colonel Glenn Hwy, Dayton, Ohio 45435, USA.
\end{abstract}

Received Date: December 21, 2021

Published Date: February 01, 2022

\begin{abstract}
Leukemia is a group of malignant disorders characterized by abnormal leukocytes proliferation and development in the bone marrow and lymphatic system. It is the most prevalent hematologic cancer in adults above 55 years and the most common cancer in the pediatric population, accounting for nearly one-third of the cases. The five-year relative survival rates have enhanced over the years to 65.0\% (2011-2017) through the application of therapeutic methodologies of standard chemotherapy. However, the prognosis of leukemia in geriatrics remains poor, with overall survival being only 5-10\% in Acute Myeloid Leukemia (AML). Despite introducing new chemotherapeutic medications and hematopoietic stem cell transplantation, the events of cancer relapse, multi-drug resistance, suboptimal response, and severe adverse effects remain significant events for some patients. Thus, it is critical to investigate alternative treatment options with improved efficacy, reduced toxicity, and multitarget combinations of chemotherapeutic medications, maybe with distinct mechanisms involved, to optimize the outcome of leukemia patients. This review discusses the recently studied herbal medicines exhibiting potential apoptosis and anti-cancer effect on the leukemia cell lines. After using PubMed's Advanced Search features with keywords such as "Herbal Medicine," "Acute myeloid leukemia," "Acute lymphocytic leukemia," "Chronic myeloid leukemia," "Chronic lymphocytic leukemia," we refined our search with the publication date range from 2017-2021 and entered articles into this review. Study selection was made based on Cochrane library guidelines to arrive at 13 final articles selection, comprising nine different herbs. The study details underlying mechanisms governing their anti-cancer effects, and corresponding biological effects.
\end{abstract}

Keywords: Herbal Medicine; Acute myeloid leukemia; Acute lymphocytic leukemia; Chronic myeloid leukemia; Apoptosis

Abbreviations: AAE: Artemisia Annua Extract; ACLE: Annona cherimola leaf extract; AML: Acute myeloid leukemia; ALL: Acute lymphoblastic leukemia; Bax: BLC2 associated X; BLC2: B-cell lymphoma 2; Bcl-xl: B-cell lymphoma-extra-large; BCR-ABL: Breakpoint cluster region-abelson; CLL: Chronic lymphocytic leukemia; CML: Chronic myeloid leukemia; Hsp90: Heat shock protein 90; ERK 1/2: Extracellular signal regulated protein kinase; EVI1: Ecotropic Viral Integration Site 1 gene; FASN: Fatty acid synthase; FLT3: Fms Related Receptor Tyrosine Kinase 3; FLT3-ITD: ITD mutation in FLT3; G0/G1: Gap 0 phase/Gap 1 phase; G0/S: Gap 0 phase /Synthesis phase; IC50: Half-maximal inhibitory concentration; ISOL: Isoliquiritigenin; ITD: Internal tandem duplication; LC3: Microtubule-associated protein light chain 3; MAPK: mitogen-activated protein kinase; Mcl-1: Myeloid-cell leukemia 1; MMP: Matrix metalloproteinases; mTOR: Mammalian target of rapamycin; PARP: Poly (ADP-ribose) polymerase-1; PI3K: phosphoinositide 3-kinase; PTEN: Phosphatase and tensin homolog; STAT5: Signal transducer and activator of transcription 5; TKI: tyrosine kinase inhibitor

\section{Opinion}

Leukemia is classified into four categories depending on if it is acute or chronic, and whether it is myeloid or lymphocytic: Acute myeloid leukemia (AML), Chronic myeloid leukemia (CML), Acute lymphoblastic leukemia (ALL), and Chronic lymphocytic leukemia (CLL). AML is characterized by the clonal expansion of immature

myeloid precursor cells that compromises the formation of normal blood cells. Although the pathophysiology of AML remains unknown, medical researchers believe that other hematological ailments, chemical contaminants, radiation, and mutations, are significant risk factors for the disease [1,2]. For long, $7+3$ combination 
intensive chemotherapy seems to be the mainstay therapy for geriatric AML patients [3]. Overall, the prognosis for geriatric AML patients is not favorable. Low-intensity chemotherapy has also been considered a therapeutic option for geriatric AML patients. However, geriatric AML patients' outcomes have not been as good as young adults [4]. Per some studies, intensive chemotherapy may not be advantageous to geriatric AML patients above 70 and could even be detrimental $[5,6]$. A Medicare beneficiary observational study shows that more than half of geriatric AML patients prefer to stay untreated [7]. Hematopoietic stem cell transplantation (HSCT) seems to be the most optimum therapy option for AML, but that is contingent on the patients' health and the availability of a stem cell donor. As a result, it is critical to develop novel and successful AML treatment techniques.

Acute lymphoblastic leukemia (ALL) is a hematological cancer typified by defective lymphoid cell progenitors' development and proliferation [8]. The overall survival rate for newly diagnosed pediatric ALL in developed nations has increased by $70 \%$ [9]. However, cancer recurrence has consistently been a complex challenge in cancer care [10]. Another crucial stumbling block to effective chemotherapy in ALL is multi-drug resistance, leading to relapse [11]. Therefore, it is not unexpected that innovative tactics for overcoming these side effects, such as adopting combination therapy, have received a lot of coverage. In addition, herbal extracts are credible options for treatments given the complex variety of phytochemicals and may be used as possible synergistic agents.

Chronic myeloid leukemia (CML) is a malignant myeloproliferative disorder initiated by a chromosomal translocation $(9 ; 22)$, resulting in the active breakpoint cluster region-abelson (BCR-ABL) tyrosine kinase [12]. This event stimulates a fusion of the BCR-ABL genes and an atypical tyrosine kinase generation, promoting dysfunctional myelopoiesis in CML and resistance to chemotherapeutic drugs [13]. Chemotherapy remains the principal treatment preference for CML patients. The introduction of new chemotherapeutic medications and hematopoietic stem cell transplantation results in one-third of CML patients relapsing after remission. The tyrosine kinase inhibitor (TKI) imatinib is utilized as the primary therapy in the therapy of CML. Unfortunately, acquiring imatinib resistance is a significant event for some patients [14]. 38\% of patients required a transition from imatinib to a second-generation TKI because of inadequate response or due to adverse events [15]. Thus, it is critical to look for alternative options to overcome resistance. (Table 1)

Table 1: Phytochemicals or Herbs exhibiting anti-apoptotic effects on ALL cell lines.

\begin{tabular}{|c|c|c|c|c|c|}
\hline Medicinal herb or Phytochemical & Model \& Study mode & Concentration & Mechanism & Biological effect & Reference \\
\hline \multirow{2}{*}{ Artemisia Аnпиа } & $\begin{array}{l}\text { a) Nalm-6 } \\
\text { b) Reh }\end{array}$ & $\begin{array}{l}\text { a) } \mathrm{IC}_{50}: 70 \mu \mathrm{g} / \\
\mathrm{ml}(48 \mathrm{hr})\end{array}$ & $\begin{array}{l}\uparrow \text { Pro-apoptotic proteins: } \\
\text { Caspase- } 3 \text { and Bax }\end{array}$ & $\uparrow$ Apoptosis & \multirow{2}{*}{ [19] } \\
\hline & In-Vitro & $\begin{array}{l}\text { b) IC } \mathrm{IC}_{50} 70 \mu \mathrm{g} / \\
\mathrm{ml}(48 \mathrm{hr})\end{array}$ & $\begin{array}{c}\downarrow \text { Anti-apoptotic protein: } \\
\text { Bcl-2 }\end{array}$ & & \\
\hline \multirow[b]{2}{*}{ Ginger } & $\begin{array}{l}\text { a) CCRF-CEM b) } \\
\text { Nalm-6 }\end{array}$ & $\begin{array}{l}\text { a) } \mathrm{IC}_{50}: 167 \mu \mathrm{g} / \\
\mathrm{ml}(48 \mathrm{hr})\end{array}$ & \multirow[b]{2}{*}{ Not Determined } & $\uparrow$ Apoptosis & \multirow[b]{2}{*}{ [20] } \\
\hline & In-Vitro & $\begin{array}{c}\text { b) } \mathrm{IC}_{50} \\
70 \mu \mathrm{g} / \mathrm{ml}(48 \\
\mathrm{hr})\end{array}$ & & & \\
\hline \multirow[b]{2}{*}{ Ginger } & a) CCRF-CEM/MRD & \multirow{2}{*}{$\begin{array}{c}1,000 \mu \mathrm{M} \\
\text { dexamethasone } \\
+167 \mu \mathrm{g} / \mathrm{ml} \\
\text { ginger extract } \\
(72 \mathrm{~h})\end{array}$} & \multirow[b]{2}{*}{$\downarrow$ FASN } & $\uparrow$ Apoptosis & \multirow[b]{2}{*}[25]{} \\
\hline & In-Vitro & & & $\begin{array}{l}\downarrow \text { De-novo fatty } \\
\text { acid production }\end{array}$ & \\
\hline
\end{tabular}

Abbreviation: $\mathrm{IC}_{50}$ : Half-maximal inhibitory concentration; Bax: BLC2 associated X; BLC2: B-cell lymphoma 2; FASN: Fatty acid synthase

Study selection was based on Cochrane library guidelines for systematic reviews. The primary papers obtained after PubMed database searching were screened to remove the duplicates, irrelevant and review articles. Dialogue and general agreement were used to address differences. The complete text files of filtered papers were thoroughly examined to ensure that only relevant research articles were chosen for quality evaluation and data retrieval within the review. Unfortunately, relevant herbal research on CLL has not progressed significantly. Due to the adherence to this process, we excluded research pertaining to CLL in this review.

\section{Herbs Targeting ALL Cell Lines}

\section{Artemisia Annua}

Various recent investigations have revealed the growth inhibitory action of numerous Artemisia species on human cell lines. Dichloromethane and petroleum ether extracts of Artemisia ciniformis displayed cytotoxic activity on leukemic cell lines [16]. Artemisinin, an extracted molecule from Artemisia annua and its derivatives, exhibited significant anti-cancer properties [17]. Artemisia Annua Extract (AAE) lowered the survival rate of T-lymphocytic leukemic cells in a dose-dependent fashion [18]. 
According to a recent study, a single dosage of methanolic AAE had an anti-leukemic action in both ALL-derived cells of Nalm-6 and Reh in a time and concentration-dependent fashion. Notably, the extract's proliferation inhibitory effect was amplified when coupled with Vincristine via caspase-3-dependent cell death. In addition, the extract upregulated caspase- 3 and Bax, the essential genes engaged in the apoptotic signaling, accompanied by an apparent inhibitory action on the transcriptional action of the antiapoptotic gene, Bcl-2. As a result, AAE increased Vincristine caused cytotoxic effects by modifying Bax and Bcl-2 mRNA expression [19].

\section{Ginger}

A recent study looked at the cytotoxicity of herbal extracts when combined with methotrexate, an extensively used chemotherapy drug. Notably, the methotrexate-resistant sub-line CCRF-CEM was more sensitive to ginger than cinnamon or green tea extracts [20]. Compared to methotrexate alone, the anti-proliferative impact of ginger extract and methotrexate combination demonstrated a considerably stronger growth suppression effect. For the CCRFCEM, Nalm-6, and ALL primary cells, the combination therapy with ginger and methotrexate showed synergistic effects. In a dose-dependent fashion, methotrexate-resistant cells were more sensitive to higher concentrations of the ginger extract than the non-resistant T lymphoblastoid cell line of CCRF-CEM [20].

The characterization of several malignancies is done by enhanced de-novo fatty acid production [21]. Fatty acid synthase (FASN) is an enzyme that catalyzes palmitate biosynthesis Upregulated FASN leads to a worse prognostic outcome and a higher chance of cancer relapse in a broad range of malignancies [22]. Furthermore, increased expression of FASN has been linked to the development of multi-drug resistance. Latter is among the most significant barrier to effective anti-cancer therapy, especially among children with ALL $[23,24]$. In a recent study, FASN was extensively upregulated in the multidrug-resistant group. The apoptotic pace was notably more in ginger-treated cells than in the control treatment. Furthermore, the cells subjected to ginger had reduced FASN expression.

Interestingly, the cotreatment of ginger plus dexamethasone reduced FASN expression and inhibited cell proliferation [25]. Furthermore, another study indicated that gingerol, a ginger metabolite, inhibits de-novo fat production, leading to mitochondrial malfunction and apoptosis in HepG2 cells [26]. These observations might open the path for more effective drug combinations to tackle leukemia drug resistance.

\section{Herbs Targeting AML Cell Lines}

\section{Ailanthone}

In a recent study, AML cells underwent apoptosis when exposed to ailanthone. In high concentrations, there was significant inhibitory action on cell survival. Ailanthone treatment of AML cell lines (KG-1, HL-60) boosted caspase cleavage, implying that ailanthone has pro-apoptotic effects on AML cell lines [27]. Furthermore, Ailanthone activated caspase-9, which further activated caspase- 3 and -7 , causing apoptosis via the intrinsic route [27]. As a result, it was suggested that ailanthone could be a viable drug for treating AML by inhibiting apoptosis.

Two crucial mechanisms in the growth of cancer include migration and invasion. Matrix metalloproteinases (MMP) are essential regulators in tumor metastasis because they aid in the disintegration of extracellular matrix components and enable cells to pass through its protein fibers to enter farther target regions [28]. MMP-9 or $92 \mathrm{kDa}$ gelatinase binding, whether endogenous or exogenous, prevent lymphocytic leukemia cells from migrating by targeting CD99 [29]. Vimentin is a coiled intermediate filament protein found in mesenchymal cells. Vimentin phosphorylation encourages cell proliferation and migration, a well-coordinated operation that includes PI3K/AKT signaling [30]. Ailanthone reportedly inhibited the migration and proliferation of AML cells by inhibiting PI3K/AKT pathway [31]. This may have been accomplished by inhibiting MMP-9 and Vimentin .

miRNAs play an essential regulatory role in AML [32]. mIR-449a is a key target of the locus protein called Ecotropic Viral Integration Site 1 gene (EVI1) in the pathophysiology of AML and CML. Besides, NOTCH1 and Bcl-2 were significant novel targets of mIR-449a [33]. miR-449 became considerably upregulated in AML cells post ailanthone administration. Furthermore, findings showed that the anti-cancer actions of Aailanthone were significantly decreased by miR-449a silencing. These findings suggested that ailanthones antiAML properties may be linked to increased miR-449a generated by ailanthone administration [27]. Thus, it is proposed that ailanthone mediated its anti-cancer effects via upregulating miR-449a, inhibiting the Notch and PI3K/AKT signal transduction pathways.

In another study, Ailanthone increased apoptosis of HL-60 cells by triggering autophagy [34]. The experimental group had acidic vesicular organelles, which are among the hallmarks of autophagy. The autophagy-related proteins Beclin1 and cytoplasmic LC3 had their protein expression raised, while the autophagic cargo p62 and autophagosome function marker LC3I had their levels downregulated in a concentration-dependent fashion [34]. As a result, the researchers suggested that Ailanthone triggered autophagy and a possible treatment for AML.

\section{Arsenic containing Quinghuang powder}

A retrospective study looked at the survival rates of geriatric AML patients treated with low-intensity chemotherapy or arseniccontaining Qinghuang powder [35]. In low-intensity chemotherapy patients, the occurrence of myelosuppression, gastrointestinal tract distress, and cardiac injury was considerably higher than in Qinghuang powder-received patients. Qinghuang powder therapy was as successful as low-intensity chemotherapy in achieving a better survival rate [35]. Furthermore, Qinghuang powder comes with the benefit of oral administration, making it more patient- 
compliant. Enhancing the proportion of the Realgar component of Qinghuang powder, which includes a very high concentration of arsenic disulfide, was shown to improve the therapeutic impact of Qinghuang powder. In F-36p cells derived from AML patients, arsenic disulfide was shown to decrease proliferation, promote cell death, and stimulate erythropoiesis at the same time [36]. Arsenic disulfide caused differentiation in HL-60 cells, and oxidative stress linked with glutathione synthetase deficiency and p38 mitogenactivated protein kinase (MAPK) stimulation were implicated in arsenic disulfide mediated differentiation [37]. Hence, it has been proposed that Qinghuang powder is efficacious in myeloid malignancies and that arsenic disulfide is responsible for its therapeutic value [35].

\section{Parris forrestii}

Total saponins extracted from Paris forrestii suppressed AML cell growth more effectively than individual saponins [38] They reduced the leukemic cell lines viability and caused very high apoptosis in various cell lines, like K562 and HL-60, which caused AML cell death. Total saponins downregulated antiapoptotic proteins $\mathrm{Mcl}-1, \mathrm{Bcl}-\mathrm{xL}$, and $\mathrm{Bcl}-2$ while increasing antioncogenic proteins such as p53 and Beclin 1 [38]. The AKT/ mammalian target of rapamycin (mTOR) axis is commonly active in AML, encouraging cell proliferation. The AKT/mTOR components are prospective therapeutic targets for leukemia [39]. The total saponins from Paris forrestii remarkably reduced AKT levels and mTOR phosphorylation in AML cells and decreased the phosphorylated 4EBP-1 and p70S6K, which are the critical downstream components of the AKT/mTOR signaling cascade [38]. Thus, total saponins suppress the AKT/mTOR signaling pathway. RNF6 is an oncoprotein involved in hematologic cell proliferation and metastasis [40]. According to Cancer Genome Atlas data, RNF6 expression was significantly negatively correlated to the survival rate of AML patients [41]. The downregulation of RNF6 was linked to AKT/mTOR signaling inactivation by total saponins from Paris forrestii [38]. RNF6 stimulated AKT/mTOR and activated the AKT/ mTOR pathway. Total saponins of Paris forrestii also inhibited the development of AML xenotransplants in nude mice. Biochemical investigations revealed that oral treatment virtually completely reduced tumor development without causing observable toxicity [38]. Thus, it presents itself as a potential safe therapy for AML.

\section{Annona Cherimola}

Annona cherimola is a semi-deciduous tree having syncarpous fruits [42]. AML cells treated with Annona cherimola seeds high in anonaceous acetogenins had anti-proliferative and intrinsic and extrinsic apoptosis-inducing actions [43]. Treatment with alcoholic extract of Annona cherimola seeds suppressed the development of KG-1 AML cell lines in a concentration-dependent fashion. In addition, it increased cell apoptosis by increasing pro-apoptotic proteins that govern mitochondrial and extrinsic apoptotic pathways [43].
A recent in-vitro study of Annona cherimola leaf extract's (ACLE) anti-proliferative and anti-cancer efficacy in AML cell lines found rising ACLE concentrations with incubation times, the KG-1 cell line proliferation in AML was significantly reduced [44]. Alongside the cell cycle arrest and the reversing of phosphatidylserine to the outer leaflet, this drop in viability coincided with a considerable rise in apoptosis. Normal mononuclear cells showed a considerably lesser effect on proliferation when treated with ACLE, demonstrating that the extract had a selective action on AML cell lines. Pro-apoptotic proteins such as cleaved caspase-8, cleaved Poly (ADP-ribose) polymerase-1 (PARP-1), and Bax and anti-apoptotic proteins such as Bcl-2 were upregulated and downregulated in AML cells, respectively, confirming the apoptotic pathway caused by ACLE. The rise of the Bax to $\mathrm{Bcl}-2$ proportion also signified that ACLE triggered apoptosis through the intrinsic route [44]. Thus, the concentration-dependent apoptotic action of the ACLE in KG-1 cells was evidenced by these changes in expression levels. Both the pro-apoptotic Bax and the anti-apoptotic Bcl-2 are engaged in modulating mitochondrial membrane permeability, which causes the discharge of cytochrome-c, which causes the breakdown of procaspase-9 and thus its activation [45]. Since an elevation of PARP-1, Bax, caspases-8, and -9 were detected amid a reduction in Bcl-2, it was suggested that ACLE causes apoptosis via both the extrinsic and intrinsic pathways [46].

\section{Licorice}

AML's high relapse risks are majorly due to epigenetic heterogeneity affecting cytosine methylation and chemoresistance permitting mutations mainly due to stimulation of activation of the IL-6/STAT3 axis [46], [47]. Furthermore, activating mutations within the FMS-like tyrosine kinase-3 (FLT3) gene are found in roughly $30 \%$ of AML patients [48]. Internal tandem duplication mutations in the FLT3 kinase (FLT3-ITD) are the most common mutations that cause metastasis [49]. Patients having elevated FLT3- ITD allelic ratios had a higher risk of relapse, a usual poor prognosis, and lower survivability [50].

Isoliquiritigenin (ISOL) is a flavonoid derived from licorice root [51]. In a dose-dependent way, ISOL decreased the viability of FLT3ITD mutated AML cell lines, notably MV4-11 and MOLM-13 [52]. FLT3 inhibition by ISOL happens in an ATP-competitive manner. ISOL suppressed the multiplication of ITD mutant FLT3 gene forms in $\mathrm{Ba} / \mathrm{F} 3$ cells (Ba/F3-FLT3-ITD cells) while being harmless to $\mathrm{Ba} /$ F3 cells. IL-3, on the other hand, was able to rescue Ba/F3-FLT3ITD cells from ISOL's anti-proliferative actions [52]. As a result, IOSL selectively decreased cell proliferation in Ba/F3 cells via FLT3 targetting and had not affected other kinases in the IL-3 receptor signal transduction pathways. The FLT3-ITD/TKD dual mutation is still the most significant reason for FLT3 antagonist resistance. FLT3-ITD F691L has a very high resistance level to the FLT3 antagonists AC220 and sorafenib [53]. ISOL suppressed the growth of Ba/F3-FLT3-ITD/F691L cells [52]. As a result, IOSL might be 
employed as a therapeutically active agent in people with FLT3-ITD mutation and those with the FLT3-ITD/TKD dual mutation. In AML cells, IOSL caused G0/G1 phase arrest and induced apoptosis. Thus, IOSL exhibited its anti-leukemic activity through targeting FLT3 on

Table 2: Phytochemicals or Herbs exhibiting anti-apoptotic effects on ALL cell lines.

\begin{tabular}{|c|c|c|c|c|c|}
\hline Medicinal herb or Phytochemical & Model \& Study model & Concentration & Mechanism & Biological effect & Reference \\
\hline \multirow{4}{*}{ Ailanthone } & a) HL-60 & $\begin{array}{l}\text { a) } \mathrm{IC}_{50}: 12.18 \mu \mathrm{M} \\
\quad(24 \mathrm{~h})\end{array}$ & $\begin{array}{l}\uparrow \text { Autophagy regulating } \\
\text { protein: Beclin-1 }\end{array}$ & $\begin{array}{c}\uparrow \text { Apoptosis in- } \\
\text { duced by autoph- } \\
\text { agy. }\end{array}$ & \multirow{4}{*}[34]{} \\
\hline & In-Vitro & $\begin{array}{c}\text { b) } \mathrm{IC}_{50}: 8.49 \mu \mathrm{M} \\
(48 \mathrm{~h})\end{array}$ & $\begin{array}{l}\downarrow \text { Autophagosome cargo } \\
\text { protein: p62 }\end{array}$ & $\downarrow$ Proliferation & \\
\hline & & $\begin{array}{l}\text { c) } \mathrm{IC}_{50}: 5.98 \mu \mathrm{M} \\
(72 \mathrm{~h})\end{array}$ & $\downarrow$ LC3-I/II & $\begin{array}{l}\uparrow \mathrm{G} 0 / \mathrm{G} 1 \text { phase } \\
\text { arrest }\end{array}$ & \\
\hline & & & & $\uparrow$ Autophagy & \\
\hline \multirow{3}{*}{ Ailanthone } & a) KG-1 & $\begin{array}{l}\text { a) } \mathrm{IC}_{50}: 0.58 \mu \mathrm{M} \\
\quad(48 \mathrm{~h})\end{array}$ & $\begin{array}{l}\uparrow \text { Pro-apoptotic pro- } \\
\text { teins: Caspase- } 3,-7 \text {, } \\
\text { and }-9 \text {. }\end{array}$ & $\uparrow$ Apoptosis & \multirow{3}{*}[27]{} \\
\hline & b) HL-60 & $\begin{array}{c}\text { b) } \mathrm{IC}_{50}: 0.57 \mu \mathrm{M} \\
(48 \mathrm{~h})\end{array}$ & $\uparrow \mathrm{miR}-449 \mathrm{a}$ & $\begin{array}{l}\downarrow \text { Proliferation and } \\
\text { migration }\end{array}$ & \\
\hline & In-Vitro & & $\begin{array}{l}\downarrow \text { NOTCH and PI3K/AKT } \\
\text { signaling }\end{array}$ & & \\
\hline \multirow{2}{*}{$\begin{array}{l}\text { Arsenic-containing Qinghuang } \\
\text { powder }\end{array}$} & In-Vivo & $\begin{array}{l}0.1 \text { Realgar and } \\
0.2 \mathrm{~g}\end{array}$ & \multirow[b]{2}{*}{ Not Determined } & $\begin{array}{l}\uparrow \text { Overall Survival } \\
\text { rate. }\end{array}$ & \multirow[b]{2}{*}[35]{} \\
\hline & & $\begin{array}{l}\text { Indigo Naturalis } \\
\text { (3 months, two } \\
\text { courses) }\end{array}$ & & $\uparrow$ Autophagy & \\
\hline \multirow{4}{*}{ Total saponins of Parris forrestii } & $\begin{array}{l}\text { a) K562 } \\
\text { b) HL-60 } \\
\text { c) KG-1 } \\
\text { d) HT-93 cells }\end{array}$ & 0 to $8 \mathrm{mg} / \mathrm{ml}(24 \mathrm{~h})$ & $\begin{array}{c}\uparrow \text { Pro-apoptotic pro- } \\
\text { teins: Caspase- } 3 \text { and } \\
\text { Bax. }\end{array}$ & $\uparrow$ Apoptosis & \multirow{4}{*}[38]{} \\
\hline & \multirow[t]{3}{*}{ In-Vitro } & & $\begin{array}{c}\downarrow \text { Anti-apoptotic pro- } \\
\text { teins: Mcl-1, Bcl-xL, and } \\
\text { Bcl-2 }\end{array}$ & $\downarrow$ Proliferation & \\
\hline & & & $\begin{array}{l}\uparrow \text { Tumor suppressor } \\
\text { proteins: p27 and p53. }\end{array}$ & & \\
\hline & & & $\begin{array}{c}\downarrow \text { RNF6/AKT/mTOR } \\
\text { pathway signaling }\end{array}$ & & \\
\hline \multirow{4}{*}{ Annona Cherimola } & a) KG-1 & $\begin{array}{l}\mathrm{IC}_{50}: 5.03 \%(\mathrm{v} / \mathrm{v} \\
24 \mathrm{~h})\end{array}$ & $\begin{array}{c}\uparrow \text { Pro-apoptotic } \\
\text { proteins: Cleaved } \\
\text { Caspase-8, cleaved } \\
\text { PARP-1, and Bax. }\end{array}$ & $\begin{array}{l}\uparrow \text { Apoptosis } \\
\text { induced via mito- } \\
\text { chondrial route. }\end{array}$ & \multirow{4}{*}[44]{} \\
\hline & \multirow{3}{*}{ In-Vitro } & & $\begin{array}{l}\downarrow \text { Anti-apoptotic pro- } \\
\text { teins: Bcl-2 }\end{array}$ & & \\
\hline & & & $\uparrow \mathrm{Bax} / \mathrm{Bcl}-2$ & & \\
\hline & & & $\uparrow \mathrm{G} 0 / \mathrm{S}$ cycle arrest & & \\
\hline \multirow{5}{*}{$\begin{array}{l}\text { Isoliquiritigenin or ISOL extracted } \\
\text { from Licorice }\end{array}$} & In-Vitro: & $\begin{array}{l}\text { a) } \mathrm{IC}_{50}: 3.20 \mu \mathrm{M} \\
(24 \mathrm{~h})\end{array}$ & $\downarrow$ FLT3 signaling & $\uparrow$ Apoptosis & \multirow{5}{*}[52]{} \\
\hline & MYA 11 & & $\uparrow \mathrm{G} 0 / \mathrm{G} 1$ cycle arrest & $\downarrow$ Proliferation & \\
\hline & b) MOLM-13 & $\begin{array}{l}\text { b) } \mathrm{IC}_{50}: 4.90 \mu \mathrm{M} \\
(24 \mathrm{~h})\end{array}$ & $\begin{array}{c}\downarrow \text { Proliferation of Ba/ } \\
\text { F3-FLT3-ITD Cells }\end{array}$ & & \\
\hline & \multirow[t]{2}{*}{ In-Vivo: MV4-11 } & $\begin{array}{c}\text { ISOL at } 100 \mathrm{mg} / \mathrm{kg} / \\
\text { day vs. Sunitinb at } \\
10 \mathrm{mg} / \mathrm{kg} / \text { day }\end{array}$ & $\begin{array}{c}\text { Maximum tumor inhibi- } \\
\text { tion rate: ISOL }(83.2 \%) \\
\text { vs. Sunitinb }(84.9 \%)\end{array}$ & & \\
\hline & & & $\downarrow$ Ki67 & & \\
\hline
\end{tabular}

Abbreviation: $\mathrm{IC}_{50}$ : Half-maximal inhibitory concentration; LC3: Microtubule-associated protein light chain 3; miR: microRNA; PI3K: phosphoinositide 3-kinase; Mcl-1: Myeloid-cell leukemia 1; Bcl-xl: B-cell lymphoma-extra-large; Bcl-2: B-cell lymphoma 2; Bax: Bcl-2 Associated X; G/S: Gap 0 phase /Synthesis phase; FLT3: Fms Related Receptor Tyrosine Kinase 3; $\mathrm{G}_{0} / \mathrm{G}_{1}$ : Gap 0 phase/ Gap 1 phase; ITD: Internal tandem duplication; FLT3-ITD: ITD mutation in FLT3; ISOL: Isoliquiritigenin 


\section{Herbs Targeting CML Cell Lines}

\section{Lotus Plumule}

The reciprocal translocation across chromosomes 9 and 22 causes most CML patients to be Philadelphia-Positive $(\mathrm{Ph}+)$ [12]. This fusion produces the BCR-ABL fusion gene. It encodes the p210 or p185 BCR-ABL1 protein, which has a dysregulated phosphorylation of tyrosine residues by tyrosine kinase and facilitates the advancement of CML [54]. Imatinib binds to the ATP domain of the p210BCR-ABL1 protein and prevents the substrate from entering the kinase site. Thus, a primary therapy for Ph+ CML patients in the initial diagnosis is Imatinib [55]. Imatinib resistance is common with long-term therapy [56,57], particularly during the advanced phases of CML- blast crisis and accelerated phase [58,59]. Imatinib resistance involves BCR-ABL1 gene amplification and somatic single nucleotide variations in the catalytic domain of the BCR-ABL1 that averts imatinib from interacting with BCR-ABL and activating the p210 BCR-ABL1's kinase activity [60]. The chaperon protein known as Heat shock protein 90 (Hsp90), molecular chaperone, is mandatory for accurate BCR-ABL folding [61]. It is during leukemias that upregulation of Hsp90 is observed [62]. Hsp90 antagonists disrupt the interaction of BCR-ABL with Hsp90, leading to BCR-ABL cleavage by the ubiquitin-proteasome pathway (UPP), resolving resistance to imatinib resistance in T3151 mutated chronic leukemia cells [63].

Lotus plumule contains neferine, a bisbenzylisoquinoline alkaloid shown to have anti-cancer properties in past years $[64,65]$. Neferine suppressed the development of CML cell lines of K562 [66]. Neferine decreases cellular proliferation in the primary CML cells in a concentration-reliant fashion and increases proliferation inhibition with imatinib [67]. In primary CML Cell lines, a combination of neferine with imatinib downregulated BCRABL1 and Hsp90. HspAA1 and HspAB are the two major isoforms of mammalian Hsp90 [68]. As relative to imatinib monotherapy, the mRNA levels of these isoforms and the protein expression of Hsp90 were significantly lower in the cotreatment group. Neferine inhibited Erk1/2 phosphorylation, implying its usefulness as an Erk1/2 antagonist in CML therapy [67].

\section{Emodin}

Several downstream signaling cascades, such as those involving STAT proteins, and phosphatidylinositol 3-kinases (PI3K) pathways, are stimulated by BCR-ABL, reducing the susceptibility of cells resistant to apoptosis. The activation of PI3K by receptor tyrosine kinases enables the phosphorylation of PIP2 to PIP3 (Phosphatidylinositol-3,4,5-trisphosphate), which is a crucial intracellular signaling molecule that that attracts downstream effectors such as AKT [69]. The involvement of the PI3K signaling in oncogenesis and apoptotic inhibition has been widely studied [70,71]. The PTEN/PI3K/AKT signaling pathway regulates apoptosis and cell proliferation. Phosphatase and tensin homolog (PTEN) is a lipid phosphatase that can inhibit the pro-apoptotic PI3K/AKT pathway via the accumulation of PIP3. PTEN regulates growth inhibitory actions through the PI3K/AKT pathway [72]. Emodin is an anthraquinone derivative derived from Rheum palmatum. A recent study on the K562 cell line discovered that Emodin induced apoptosis by inhibiting the PI3K/AKT, upregulating the expression of PTEN, and causing BCR-ABL deletion [73]. Compared to the control, Emodin had decreased the viability of K562 cells in a concentration-reliant fashion. In-vitro, cycle arrest was caused by Emodin during the G0/G1 phase. Emodin increased the cell number in the G1 phase while decreasing it in the diploid zones in a concentration-dependent fashion. As a result, it was suggested that Emodin might cause an apoptotic process in proliferating cells. Emodin triggered apoptosis in K562 cells in-vitro and successfully reduced tumor progression in nude mice in-vivo with no apparent adverse effects [73]. The mechanism underlying emodin-mediated inhibition of cellular growth in CML cells ate related to Emodin concentration-dependently lowering BCR-ABL expression. The degree of PI3K/AKT inhibition was linked to an increase in emodintriggered apoptotic episodes. Intriguingly, Emodin did not cause significant cytotoxicity in normal human cells, implying that it had a tumor-selective anti-proliferative action [73].

STAT5 is a vital signal transducer in hematologic malignancies [74]. According to many studies, STAT5 activity is critical for leukemic cell viability and TKI resistance in CML cells [75,76]. Upregulation of STAT5 causes resistance to tyrosine kinase inhibitors in leukemic cells, preventing any TKI caused adverse effects [75]. STAT5 has lately emerged as a promising therapeutic target for overcoming BCR-ABL1 kinase antagonist resistance, such as in CML cells with the T315I mutated BCR-ABL [75]. The cotreatment of kinase inhibitor imatinib and Emodin attenuated STAT5 phosphorylation in a concentration-dependent fashion [77]. Emodin might actively decrease resistance to imatinib by the K562/G01 cell line via downregulating BCR-ABL1 expression and STAT5 phosphorylation. Emodin is known to have augmented the antagonizing actions of imatinib on the STAT5 signaling and mitogenic BCR-ABL1 pathway in the K562/G01 cells [77]. Researchers suggested that the downregulation of anti-apoptotic protein Mcl-1and proto-oncogene c-MYC were associated with reduced expression of BCR-ABL1 and STAT5. The cleavage of nuclear enzyme PARP, stimulation of apoptotic mediator caspase-3, and reduced expression of apoptosis regulator Bcl-2 demonstrated that imatinib-emodin's cotreatment caused apoptosis. The upregulated Src kinases coordinate alongside BCR-ABL1 kinase in inducing STAT5 for CML cell transformation and imatinib resistance [78,79]. It was shown that downregulated Src activity and phosphorylation were behind the augmented activity of imatinib when co-administered with Emodin [77].

The Multidrug resistance phenotype is typically related to the upregulation of drug efflux pump glycoprotein known as P-glycoprotein. The latter is among the BCR/ABL-independent processes [80]. P-glycoprotein serves as an ATP-dependent efflux pump for nonpolar chemotherapeutics, including adriamycin 
[81]. Thus, several chemotherapy drugs could not concentrate sufficiently on cancer cells to achieve therapeutic levels, resulting in multi-drug resistance [82]. As a result, the development of P-glycoprotein antagonists to avoid P-glycoprotein-mediated multidrug resistance in CML is necessary. Emodin corrects multi-drug resistance in adriamycin-resistant HL-60 cells [83]. Furthermore, Emodin inhibited P-glycoprotein efflux activity in adenocarcinoma cells of the colorectal region, indicating that it can serve as a potent P-glycoprotein antagonist [84]. In adriamycin-resistant K562 cells, Emodin overcomes adriamycin resistance significantly.
The P-glycoprotein expression was reduced by Emodin alone or combined with adriamycin in a dose-dependent manner [85]. Rhodamine-123 dye is a P-glycoprotein substrate and is thus employed as a diagnostic probe in multi-drug resistance research. In adriamycin-resistant K562 cells, Emodin raised intracellular rhodamine-123 levels and competitively inhibited rhodamine-123 at the binding site of P-glycoprotein. There is a belief that Emodin is a possible P-glycoprotein substrate, and it inhibits P-glycoprotein activity through competitive inhibition [85]. As a result, Emodin could be employed to control P-glycoprotein expression. (Table 3)

Table 3: Phytochemicals or Herbs exhibiting anti-apoptotic effects on CML cell lines.

\begin{tabular}{|c|c|c|c|c|c|}
\hline $\begin{array}{l}\text { Medicinal herb or Phyto- } \\
\text { chemical }\end{array}$ & Model \& Study mode & Concentration & Mechanism & Biological effect & Reference \\
\hline \multirow{4}{*}{$\begin{array}{l}\text { Neferine extracted from } \\
\text { Lotus plumule }\end{array}$} & Primary CML cells & a) $\mathrm{IC}_{50}: 63.48 \mu \mathrm{M}(48 \mathrm{~h})$ & $\downarrow$ BCR-ABL & $\downarrow$ Proliferation & \multirow{4}{*}[67]{} \\
\hline & \multirow{3}{*}{ In-Vitro } & $\begin{array}{c}\text { b) } \mathrm{IC}_{50} \text { (Imatinib): } 0.70 \mu \mathrm{M} \\
(48 \mathrm{~h})\end{array}$ & $\downarrow$ Hsp90 & & \\
\hline & & $\begin{array}{l}\text { c) } \mathrm{IC}_{50} \text { (Imatinib }+4 \mu \mathrm{M} \\
\text { Neferine): } 0.32 \mu \mathrm{M}(48 \mathrm{~h})\end{array}$ & $\downarrow$ p-Erk1/2 & & \\
\hline & & $\begin{array}{l}\text { d) } \mathrm{IC}_{50}(\text { Imatinib }+8 \mu \mathrm{M} \\
\text { Neferine }): 0.16 \mu \mathrm{M}(48 \mathrm{~h})\end{array}$ & $\begin{array}{l}\downarrow \text { Anti-apoptotic pro- } \\
\text { teins: Mcl-1 }\end{array}$ & & \\
\hline \multirow{4}{*}{ Emodin } & In-Vitro \& In-Vivo: & $\begin{array}{l}25,50, \text { and } 100 \mu \mathrm{mol} / \mathrm{L} \\
\text { emodin }(48 \mathrm{~h}) .\end{array}$ & $\downarrow \mathrm{BCR}-\mathrm{ABL}$ & $\uparrow$ Apoptosis & \multirow{4}{*}[73]{} \\
\hline & \multirow{3}{*}{ K562 cells } & & $\uparrow$ G0/G1 cycle arrest & $\downarrow$ Proliferation & \\
\hline & & & $\downarrow$ PI3K/AKT signaling & & \\
\hline & & & $\uparrow$ PTEN & & \\
\hline \multirow{5}{*}{ Emodin } & K562/ADM cells & $\begin{array}{c}20 \text { or } 40 \mu \mathrm{M} \text { emodin and } 1 \\
\mu \mathrm{M} \text { Imatinib }(72 \mathrm{~h})\end{array}$ & $\downarrow$ BCR-ABL & $\uparrow$ Apoptosis & \multirow{5}{*}[77]{} \\
\hline & \multirow{4}{*}{ In-Vitro } & & $\downarrow$ STAT5 & & \\
\hline & & & $\downarrow \mathrm{Src}$ & & \\
\hline & & & $\begin{array}{l}\downarrow \text { Anti-apoptotic pro- } \\
\text { teins: Mcl- } 1 \text { and Bcl-2 }\end{array}$ & & \\
\hline & & & $\begin{array}{c}\uparrow \text { Pro-apoptotic } \\
\text { proteins: Cleaved } \\
\text { Caspase-3, cleaved } \\
\text { PARP }\end{array}$ & & \\
\hline \multirow{6}{*}{ Emodin } & K562/ADM cells & $\begin{array}{l}\text { a) } \mathrm{IC}_{50}(5 \mu \mathrm{g} / \mathrm{ml} \text { Adiramy- } \\
\text { cin): } 10.97 \mu \mathrm{M}(48 \mathrm{~h})\end{array}$ & & & \multirow{6}{*}[85]{} \\
\hline & In-Vitro & $\begin{array}{l}\text { b) } \mathrm{IC}_{50}(\text { Adriamycin }+1 \mu \mathrm{M} \\
\text { Emodin): } 6.35 \mu \mathrm{M}(48 \mathrm{~h})\end{array}$ & $\downarrow$ P-glycoprotein & $\uparrow$ Apoptosis & \\
\hline & & $\begin{array}{l}\text { c) } \mathrm{IC}_{50}(\text { Adriamycin }+5 \mu \mathrm{M} \\
\text { Emodin): } 4.01 \mu \mathrm{M}(48 \mathrm{~h})\end{array}$ & $\uparrow$ Rhodamine-123 & & \\
\hline & & $\begin{array}{c}\text { d) } \mathrm{IC}_{50}(\text { Adriamycin }+10 \mu \mathrm{M} \\
\text { Emodin): } 3.20 \mu \mathrm{M}(48 \mathrm{~h})\end{array}$ & & & \\
\hline & & $\begin{array}{c}\text { e) } \mathrm{IC}_{50} \text { (Adriamycin }+20 \mu \mathrm{M} \\
\text { Emodin): } 1.53 \mu \mathrm{M}(48 \mathrm{~h})\end{array}$ & & & \\
\hline & & $\begin{array}{l}\text { f) } \mathrm{IC}_{50} \text { (Adriamycin }+40 \mu \mathrm{M} \\
\text { Emodin): } 0.99 \mu \mathrm{M}(48 \mathrm{~h})\end{array}$ & & & \\
\hline
\end{tabular}

Abbreviation: $\mathrm{IC}_{50}$ : Half-maximal inhibitory concentration; BCR-ABL: breakpoint cluster region-abelson; Hsp90: Heat shock protein 90; p-ERK 1/2: extracellular signal regulated protein kinase; Mcl-1: Myeloid-cell leukemia 1; G0/G1: Gap 0 phase/ Gap 1 phase; PI3K: phosphoinositide 3-kinase; PTEN: Phosphatase and tensin homolog; STAT5: Signal transducer and activator of transcription 5; Bcl-2: B-cell lymphoma 2; PARP: Poly (ADP-ribose) polymerase-1

\section{Discussion}

Our final selected papers indicated that two herbs- Ginger and Artemesia annua- demonstrated apoptotic action on ALL cell lines.
The latter showed considerable cytotoxicity when AAE was used alone or combined with Vincristine. Thus, suggesting that using AAE in conjunction with Vincristine would allow for lower Vincristine 
concentrations, leading to lesser general toxicity in ALL treatment [19]. Nevertheless, more research in a clinical context could help to confirm the ALL's efficacy and assess the usefulness of this strategy. Almost all chemotherapy regimens include methotrexate as a central ingredient. Due to its poor pharmacokinetics and significant adverse reactions, its therapeutic success has been constrained [86]. As a result, identifying herbal medicines that demonstrated synergistic correlation with methotrexate, like ginger, could be employed as an economical alternative cancer therapeutic supplement with reduced toxicity and greater anticancerous efficacy [20]. Ginger had a selective, strong anti-proliferative effect on drug-resistant leukemic sub-lines. The findings confirmed ginger's anti-cancer properties in children with ALL, and they could pave the path for better leukemia treatments in the future [20]. FASN inhibition is a promising cancer treatment strategy [87] and targeted with combination treatment. Unfortunately, initial FASN antagonists such as cerulenin and C75 exhibit drawbacks like chemical instability, limited bioavailability, and unpleasant adverse effects, limiting their clinical usage $[87,88]$. Ginger extract could suppress FASN, overcoming dexamethasone resistance [25]. Future study is essential to uncover the mechanisms through which ginger exerts its apoptotic effect on tumor tissue.

ALL is the most extensively studied leukemia. Ailanthone acted as an anti-tumor agent by increasing the expression of miR-449a and further inhibiting the Notch/PI3K/AKT signal transduction actions [27]. More in-vivo research is needed to confirm the crosstalk between the ailanthone, miR-449a, Notch, and PI3K/ AKT signaling pathways. In F-36p cells derived from an AML patient, Arsenic disulfide found in quinghuang powder reduced proliferation, triggered apoptosis, and simultaneously enhanced erythroid differentiation. Arsenic disulfide promoted differentiation in HL-60 cells, and oxidative stress, glutathione deficiency, and p38-MAPK activation were discovered to be implicated [35]. Several studies have proven the AKT/mTOR components to be prospective therapeutic targets for malignancy. While AKT antagonists still have not been licensed for cancer therapy, many are part of clinical trials, showing considerable promise [89]. Total saponins from Parris foresstii reduced the AKT/mTOR signaling via decreasing RNF6 expression [38]. However, more research into how RNF6 stimulates the AKT/mTOR signaling remains crucial. Total saponins extracted from Parris foresstii could be explored even more as a novel therapeutic for AML patients due to its low toxicity and powerful anti-AML action. Upon the breakdown of PARP, stimulation of caspases, and the Bax/Bcl-2 fraction elevation, the intriguing pro-apoptotic activity of ACLE on AML cell lines invitro was demonstrated, with substantial antioxidant potential [44]. Numerous antioxidant phytoconstituents have anti-cancer activities, pointing to the fact that there is a link connecting the anticarcinogenic characteristics of these phytoconstituents. Although this link is not entirely understood, studies have shown that reducing oxidative stress can reduce their adverse effects on signal pathways that regulate metastasis and carcinogenesis onset; nonetheless, these mechanisms need to be researched further [90]. ISOL showed anti-AML effectiveness by targeting FLT3 both in-vitro and in-vivo [52]. As a result, it seems to assist in treating FLT3-ITD mutated AML recurrence potentially. ISOL may have better treatment effectiveness in AML when combined with other anti-AML medicines. ISOL's anti-AML properties, on the other hand, are still unknown. In addition, ISOL's possible targets are mostly unclear.

Two herbs were reported to have anti-cancer activity on CML during this study. The first was Lotus plumule. Its phytoconstituent neferine was found to have suppressed primary CML cellular proliferation in a concentration-reliant fashion. Low amounts of neferine improved the anti-cancer activity of imatinib [67]. The suppression of p210 BCR-ABL, Hsp90, and reduced expression of p-Erk and Mcl-1 could reflect the critical mechanisms of sensitization. Decreasing concentrations of p-Erk1/2 and Mcl-1 were found, but if there is indeed a link between the two must be investigated further. The second extensively studied herb on CML cell lines was emodin. Emodin induced apoptosis by inhibiting PI3K/ AKT activity, increasing expression of PTEN, and deleting BCR-ABL [73]. Emodin had a remarkable effect on inhibiting the proliferation of K562 cells by stimulating apoptosis. The findings further support the idea that the PTEN/PI3K/AKT pathway is a crucial target for anti-cancer therapeutic development. In another study, Emodin inhibited P-glycoprotein synthesis and its drug efflux activity as a substrate, thereby reversing P-glycoprotein-regulated multidrug resistance in K562/ADM cells [85]. Competitive interaction between emodin and rhodamine-123 at the R site of P-glycoprotein was present [85]. The interaction suggests that emodin could control P-glycoprotein expression. More profound investigations will be required to uncover the mechanisms of emodin within the correction of P-glycoprotein-mediated multi-drug resistance. By inhibiting the BCR-ABL/STAT5 signaling cascade and downstream components involved in apoptosis, Emodin significantly reduced imatinib stimulated apoptosis. Furthermore, emodin had a far stronger affinity for the myristoyl-binding pocket of ABL1 than for the ATP-binding region, indicating that it could augment the efficacy of imatinib [77]. As a result, emodin could become a viable chemotherapeutic drug in the treatment of CML in the future.

\section{Conclusion}

The area of cancer chemoprevention utilizing herbal extracts has substantially gained relevance due to the sheer involvement of phytochemicals that attain the ultimate therapeutic efficacy with lower overall toxicity relative to traditional chemotherapy drugs. Herbal compounds have garnered considerable attention in the treatment of leukemia. More research into the molecular events underlying the function of these phytochemicals, including suppression of the cell proliferation signaling pathway, and stimulation of apoptotic events, are being conducted. In-vivo 
investigations should be prioritized to give reliable proof of herbal remedies' efficacy in leukemia treatment and identify its underlying anti-cancer mechanism.

\section{Acknowledgement}

None.

\section{Conflict of Interest}

The authors declare no competing interests.

\section{References}

1. Poynter JN, Richardson M, Roesler M, Blair CK, Hirsch B, et al (2017) Chemical exposures and risk of acute myeloid leukemia and myelodysplastic syndromes in a population-based study. Int J Cancer140(1): 23-33.

2. Klymenko S, Trott K, Atkinson M, Bink K, Bebeshko V, et al. (2005) Aml1 Gene Rearrangements and Mutations in Radiation-Associated Acute Myeloid Leukemia and Myelodysplastic Syndromes. J Radiat Res 46(2): 249-255.

3. Dombret H, Gardin C (2016) An update of current treatments for adult acute myeloid leukemia. Blood 127(1): 53-61.

4. Almeida AM, Ramos F (2016) Acute myeloid leukemia in the older adults. Leuk Res Reports 6: 1-7.

5. Kantarjian H, Ravandi F, O’Brien S, Cortes J, Faderl S, et al. (2010) Intensive chemotherapy does not benefit most older patients (age 70 years or older) with acute myeloid leukemia. Blood 116(22): 4422-4429.

6. Griffiths EA, Carraway HE, Chandhok NS, Prebet T (2020) Advances in non-intensive chemotherapy treatment options for adults diagnosed with acute myeloid leukemia. Leuk Res 91: 106339.

7. Medeiros BC, Satram-Hoang S, Hurst D, Hoang KQ, Momin F, et al. (2015) Big data analysis of treatment patterns and outcomes among elderly acute myeloid leukemia patients in the United States. Ann Hematol 94(7): 1127-1138.

8. Terwilliger T, Abdul-Hay M (2017) Acute lymphoblastic leukemia: comprehensive review and 2017 update. Blood Cancer J 7(6): e577-e577.

9. de Rooij J, Zwaan C, van den Heuvel-Eibrink M (2015) Pediatric AML: From Biology to Clinical Management. J Clin Med 4(1): 127-149.

10. Aldoss I, Pillai R, Yang D, Yang L, Arslan S, et al. (2021) Late and very late relapsed acute lymphoblastic leukemia: clinical and molecular features, and treatment outcomes. Blood Cancer J 11(7): 125.

11. Zhang J, Gu Y, Chen B (2019) Mechanisms of drug resistance in acute myeloid leukemia. Onco Targets Ther 12: 1937-1945.

12. Kang ZJ, Liu YF, Xu LZ, Long ZJ, Huang D, et al. (2016) The Philadelphia chromosome in leukemogenesis. Chin J Cancer 35: 48.

13. Iqbal Z (2014) A comprehensive analysis of breakpoint cluster regionabelson fusion oncogene splice variants in chronic myeloid leukemia and their correlation with disease biology. Indian J Hum Genet 20(1): 64-68.

14. Milojkovic D, Apperley J (2009) Mechanisms of Resistance to Imatinib and Second-Generation Tyrosine Inhibitors in Chronic Myeloid Leukemia. Clin Cancer Res 15(24): 7519-7527.

15. Castagnetti F, Di Raimondo F, De Vivo A, Spitaleri A, Gugliotta G, et al. (2017) A population-based study of chronic myeloid leukemia patients treated with imatinib in first line. Am J Hematol 92(1): 82-87.

16. Tayarani-Najaran Z, Hajian Z, Mojarrab M, Emami SA (2014) Cytotoxic and Apoptotic Effects of Extracts of Artemisia ciniformis Krasch. \&amp; Popov ex Poljakov on K562 and HL-60 Cell Lines. Asian Pacific J Cancer Prev 15(17): 7055-7059.

17. Slezakova S, Ruda-Kucerova J (2017) Anticancer Activity of Artemisinin and its Derivatives. Anticancer Res 37(11): 5995-6003.
18. Singh N, Ferreira J, Park J, Lai H (2011) Cytotoxicity of Ethanolic Extracts of Artemisia annua to Molt-4 Human Leukemia Cells. Planta Med 77(16): 1788-1793.

19. Mashati P, Esmaeili S, Dehghan-Nayeri N, Bashash D, Darvishi M, et al. (2019) Methanolic Extract from Aerial Parts of Artemisia Annua L. Induces Cytotoxicity and Enhances Vincristine-Induced Anticancer Effect in Pre-B Acute Lymphoblastic Leukemia Cells. Int J Hematol Oncol Stem Cell Res 13(3): 132-139.

20. Rahimi Babasheikhali S, Rahgozar S, Mohammadi M (2019) Ginger extract has anti-leukemia and anti-drug resistant effects on malignant cells. J Cancer Res Clin Oncol 145(8): 1987-1998.

21. Koundouros N, Poulogiannis G (2020) Reprogramming of fatty acid metabolism in cancer. Br J Cancer 122(1): 4-22.

22. Ventura R, Mordec K, Waszczuk J, Wang Z, Lai J, et al. (2015) Inhibition of de novo Palmitate Synthesis by Fatty Acid Synthase Induces Apoptosis in Tumor Cells by Remodeling Cell Membranes, Inhibiting Signaling Pathways, and Reprogramming Gene Expression. EBioMedicine 2(8): 808-824.

23. Humbert M, Seiler K, Mosimann S, Rentsch V, Sharma K, et al. (2021) Reducing FASN expression sensitizes acute myeloid leukemia cells to differentiation therapy. Cell Death Differ 28(8): 2465-2481.

24. Humbert M, Mosimann S, Rentsch V, Tschan MP (2018) Elucidating the Non-Catalytic Function of Fatty Acid Synthase and Its AutophagyDependent Degradation in Acute Myelocytic Leukemia Differentiation Therapy. Blood 132(Suppl 1): 2624

25. Ghaeidamini Harouni M, Rahgozar S, Rahimi Babasheikhali S, Safavi A Ghodousi ES (2020) Fatty acid synthase, a novel poor prognostic factor for acute lymphoblastic leukemia which can be targeted by ginger extract. Sci Rep 10(1): 14072.

26. Impheng H, Richert L, Pekthong D, Scholfield CN, Pongcharoen S, et al. (2015) [6]-Gingerol inhibits de novo fatty acid synthesis and carnitine palmitoyltransferase-1 activity which triggers apoptosis in HepG2. Am J Cancer Res 5(4): 1319-1336.

27. Zhang Y, Zhang C, Min D (2019) Ailanthone up-regulates miR-449a to restrain acute myeloid leukemia cells growth, migration and invasion. Exp Mol Pathol 108: 114-120.

28. Gonzalez-Avila G, Sommer B, Mendoza-Posada DA, Ramos C, GarciaHernandez AA, et al. (2019) Matrix metalloproteinases participation in the metastatic process and their diagnostic and therapeutic applications in cancer. Crit Rev Oncol Hematol 137: 57-83.

29. Aguilera-Montilla N, Bailon E, Uceda-Castro R, Ugarte-Berzal E, Santos A, et al. (2019) MMP-9 affects gene expression in chronic lymphocytic leukemia revealing CD99 as an MMP-9 target and a novel partner in malignant cell migration/arrest. Oncogene 38(23): 4605-4619.

30. Zhu QS, Rosenblatt K, Huang KL, Lahat G, Brobey R, et al. (2011) Vimentin is a novel AKT1 target mediating motility and invasion. Oncogene $30(4)$ : 457-470.

31. Ding H, Yu X, Hang C, Gao K, Lao X, et al. (2020) Ailanthone: A novel potential drug for treating human cancer. Oncol Lett 20(2): 1489-1503.

32. Wallace JA O'Connell RM (2017) MicroRNAs and acute myeloid leukemia: therapeutic implications and emerging concepts. Blood 130(11): 12901301.

33. Liu K, Tirado CA (2019) MECOM: A Very Interesting Gene Involved also in Lymphoid Malignancies. J Assoc Genet Technol 45(3): 109-114.

34. Wei C, Chen C, Cheng Y, Zhu L, Wang Y, et al. (2018) Ailanthone induces autophagic and apoptotic cell death in human promyelocytic leukemia HL-60 cells. Oncol Lett 16(3): 3569-3576.

35. Fan T, Quan RC, Liu WY, Xiao HY, Tang XD, et al. (2020) Arsenic-Containing Qinghuang Powder Is An Alternative Treatment for Elderly Acute Myeloid Leukemia Patients Refusing Low-Intensity Chemotherapy. Chin J Integr Med 26(5): 339-344. 
36. Hu X, Tanaka S, Onda K, Yuan B, Toyoda H, et al. (2014) Arsenic disulfide induced apoptosis and concurrently promoted erythroid differentiation in cytokine-dependent myelodysplastic syndrome-progressed leukemia cell line F-36p with complex karyotype including monosomy 7. Chin J Integr Med 20(5): 387-393.

37. Hu XM, Yuan B, Tanaka S, Zhou Q Onda K, et al. (2014) Involvement of oxidative stress associated with glutathione depletion and p38 mitogen-activated protein kinase activation in arsenic disulfide-induced differentiation in HL-60 cells. Leuk Lymphoma 55(2): 392-404.

38. Lu Q, He Y, Wang Y, Gao L, Zheng Y, et al. (2018) Saponins From Paris forrestii (Takht.) H. Li Display Potent Activity Against Acute Myeloid Leukemia by Suppressing the RNF6/AKT/mTOR Signaling Pathway. Front Pharmacol 9: 673.

39. Nepstad I, Hatfield KJ, Grønningsæer IS, Reikvam H (2020) The PI3KAkt-mTOR Signaling Pathway in Human Acute Myeloid Leukemia (AML) Cells. Int J Mol Sci 21(8): 2907.

40. Ren Y, Xu X, Mao CY, Han KK, Xu YJ, et al. (2020) RNF6 promotes myeloma cell proliferation and survival by inducing glucocorticoid receptor polyubiquitination. Acta Pharmacol Sin 41(3): 394-403.

41. Zapolnik P, Pyrkosz A (2020) RNF6 as an Oncogene and Potential Therapeutic Target-A Review. BioTech 9(4): 22.

42. Tundis R, Xiao J, Loizzo MR (2017) Annona species (Annonaceae): a rich source of potential anti-tumor agents? Ann N Y Acad Sci 1398(1): 30-36

43. Haykal T, Nasr P, Hodroj MH, Taleb RI, Sarkis R, et al. (2019) Annona cherimola Seed Extract Activates Extrinsic and Intrinsic Apoptotic Pathways in Leukemic Cells. Toxins (Basel) 11(9): 506.

44. Haykal T, Younes M, El Khoury M, Ammoury C, Tannous S, et al. (2021) The pro-apoptotic properties of a phytonutrient rich infusion of $\mathrm{A}$ cherimola leaf extract on AML cells. Biomed Pharmacother 140: 111592

45. Karch J, Kwong JQ, Burr AD, Sargent MA, Elord JW, et al. (2013) Bax and Bak function as the outer membrane component of the mitochondrial permeability pore in regulating necrotic cell death in mice. Elife 2: e00772.

46. Li S, Mason CE, Melnick A (2016) Genetic and epigenetic heterogeneity in acute myeloid leukemia. Curr Opin Genet Dev 36: 100-106.

47. Hou D, Wang B, You R, Wang X, Liu J, et al. (2020) Stromal cells promote chemoresistance of acute myeloid leukemia cells via activation of the IL-6/STAT3/OXPHOS axis. Ann Transl Med 8(21): 1346

48. Welch JS, Ley TJ, Link DC, Miller CA, Larson DE, et al. (2012) The Origin and Evolution of Mutations in Acute Myeloid Leukemia. Cell 150(2): 264-278.

49. Marhäll A, Heidel F, Fischer T, Rönnstrand L (2018) Internal tandem duplication mutations in the tyrosine kinase domain of FLT3 display a higher oncogenic potential than the activation loop D835Y mutation. Ann Hematol 97(5): 773-780.

50. El Fakih R, Rasheed W, Hawsawi Y, Alsermani M, Hassanein M (2018) Targeting FLT3 Mutations in Acute Myeloid Leukemia. Cells 7(1): 4.

51. Lim TK (2015) Glycyrrhiza glabra. Edible Medicinal Non-Medicinal Plants: 354-457.

52. Cao ZX, Wen Y, He JL, Huang SZ, Gao F, et al. (2019) Isoliquiritigenin, an Orally Available Natural FLT3 Inhibitor from Licorice, Exhibits Selective Anti-Acute Myeloid Leukemia Efficacy In Vitro and In Vivo. Mol Pharmacol 96(5): 589-599.

53. Moore AS, Faisal A, WY Mak G, Miraki-Moud F, Bavetsias V, et al. (2020) Quizartinib-resistant FLT3-ITD acute myeloid leukemia cells are sensitive to the FLT3-Aurora kinase inhibitor CCT241736. Blood Adv 4(7): 1478-1491.

54. Brown LM, Hanna DT, Khaw SL, Ekert PG (2017) Dysregulation of BCL-2 family proteins by leukemia fusion genes. J Biol Chem 292(35): 1432514333.

55. Soverini S, Mancini M, Bavaro L, Cavo M, Martinelli G (2018) Chronic myeloid leukemia: the paradigm of targeting oncogenic tyrosine kinase signaling and counteracting resistance for successful cancer therapy. Mol Cancer 17(1): 49.

56. Hochhaus A, Larson RA, Guilhot F, Radich JP, Branford S, et al. (2017) Long-Term Outcomes of Imatinib Treatment for Chronic Myeloid Leukemia. N Engl J Med 376(10): 917-927.

57. Hoemberger M, Pitsawong W, Kern D (2020) Cumulative mechanism of several major imatinib-resistant mutations in Abl kinase. Proc Natl Acad Sci U S A 117(32): 19221-19227.

58. Bhamidipati PK, Kantarjian H, Cortes J, Cornelison AM, Jabbour E (2013) Management of imatinib-resistant patients with chronic myeloid leukemia. Ther Adv Hematol 4(2): 103-117.

59. Marum JE, Branford S (2016) Current developments in molecular monitoring in chronic myeloid leukemia. Ther Adv Hematol 7(5): 237 251.

60. Braun TP, Eide CA, Druker BJ (2020) Response and Resistance to BCRABL1-Targeted Therapies. Cancer Cell 37(4): 530-542.

61. Peng Y, Huang Z, Zhou F, Wang T, Mou K, et al. (2021) Effect of HSP90AB1 and CC domain interaction on Bcr-Abl protein cytoplasm localization and function in chronic myeloid leukemia cells. Cell Commun Signal 19(1): 71.

62. Mshaik R, Simonet J, Georgievski A, Jamal L, Bechoua S, et al. (2021) HSP90 inhibitor NVP-BEP800 affects stability of SRC kinases and growth of T-cell and B-cell acute lymphoblastic leukemias. Blood Cancer J 11(3): 61.

63. Khajapeer KV, Baskaran R (2015) Hsp90 Inhibitors for the Treatment of Chronic Myeloid Leukemia. Leuk Res Treatment 2015: 757694.

64. Shen Y, Guan Y, Song X, He J, Xie Z, et al. (2019) Polyphenols extract from lotus seedpod (Nelumbo nucifera Gaertn.): Phenolic compositions, antioxidant, and anti-proliferative activities. Food Sci Nutr 7(9): 30623070 .

65. Wang J, Dong Y, Li Q (2020) Neferine induces mitochondrial dysfunction to exert anti-proliferative and anti-invasive activities on retinoblastoma. Exp Biol Med (Maywood) 245(15): 1385-1394.

66. Qin Q, Chen XP, Yang ZS, Xiao YH, Min H, et al. (2011) Neferine increases STI571 chemosensitivity via inhibition of P-gp expression in STI571resistant K562 cells. Leuk Lymphoma 52(4): 694-700.

67. Zhang Y, Xiao Y, Dong Q Ouyang W, Qin Q (2019) Neferine in the Lotus Plumule Potentiates the Antitumor Effect of Imatinib in Primary Chronic Myeloid Leukemia Cells In Vitro. J Food Sci 84(4): 904-910.

68. Hoter A, El-Sabban M, Naim HY (2018) The HSP90 Family: Structure, Regulation, Function, and Implications in Health and Disease. Int J Mol Sci 19(9): 2560

69. Steelman LS, Pohnert SC, Shelton JG, Franklin RA, Bertrand FE, et al. (2004) JAK/STAT, Raf/MEK/ERK, PI3K/Akt and BCR-ABL in cell cycle progression and leukemogenesis. Leukemia 18(2): 189-218.

70. Glorieux M, Dok R, Nuyts S (2020) The influence of PI3K inhibition on the radiotherapy response of head and neck cancer cells. Sci Rep 10(1): 16208.

71. Li X, Dai D, Chen B, Tang H, Xie X, et al. (2018) Efficacy of PI3K/AKT/ mTOR pathway inhibitors for the treatment of advanced solid cancers: A literature-based meta-analysis of 46 randomised control trials. PLoS One 13(2): e0192464

72. Naderali E, Valipour B, Afshin Khaki A, Soleymani Rad J, Alihemmati A, et al. (2019) Positive Effects of PI3K/Akt Signaling Inhibition on PTEN and P53 in Prevention of Acute Lymphoblastic Leukemia Tumor Cells. Adv Pharm Bull 9(3): 470-480.

73. Wang CG, Zhong L, Liu YL, Shi XJ, Shi LQ et al. (2017) Emodin Exerts an Anti-apoptotic Effect on Human Chronic Myelocytic Leukemia K562 Cell Lines by Targeting the PTEN/PI3K-AKT Signaling Pathway and Deleting BCR-ABL. Integr Cancer Ther 16(4): 526-539.

74. Tolomeo M, Meli M, Grimaudo S (2020) STAT5 and STAT5 Inhibitors in Hematological Malignancies. Anticancer Agents Med Chem 19(17): 2036-2046. 
75. Gleixner KV, Schneeweiss M, Eisenwort G, Berger D, Herrmann H, et al. (2017) Combined targeting of STAT3 and STAT5: a novel approach to overcome drug resistance in chronic myeloid leukemia. Haematologica 102(9): 1519-1529.

76. Brachet-Botineau M, Deynoux M, Vallet N, Polomski M, Juen L, et al. (2019) A Novel Inhibitor of STAT5 Signaling Overcomes Chemotherapy Resistance in Myeloid Leukemia Cells. Cancers (Basel) 11(12): 2043.

77. Wang XY, Sun GB, Wang YJ, Yan F (2020) Emodin Inhibits Resistance to Imatinib by Downregulation of Bcr-Abl and STAT5 and Allosteric Inhibition in Chronic Myeloid Leukemia Cells. Biol Pharm Bull 43(10): 1526-1533.

78. Voisset E, Brenet F, Lopez S, de SepulvedaP (2020) SRC-Family Kinases in Acute Myeloid Leukaemia and Mastocytosis. Cancers (Basel) 12(7): 1996.

79. Konig H, Copland M, Chu S, Jove R, Holyoake TL, et al. (2008) Effects of Dasatinib on Src Kinase Activity and Downstream Intracellular Signaling in Primitive Chronic Myelogenous Leukemia Hematopoietic Cells. Cancer Res 68(23): 9624-9633.

80. Maia RC, Vasconcelos FC, Souza PS, Rumjanek VM (2018) Towards Comprehension of the ABCB1/P-Glycoprotein Role in Chronic Myeloid Leukemia. Molecules 23(1): 119.

81. Lai GM, Chen YN, Mickley LA, Fojo AT, Bates SE (1991) P-glycoprotein expression and schedule dependence of adriamycin cytotoxicity in human colon carcinoma cell lines. Int J Cancer 49(5): 696-703.

82. Feng Y, Hu Y, Cen J, Darshika KN, Fang W, et al. (2013) HZ08 inhibits the multi-drug resistance on multiple sites as the substrate of p-glycoprotein Eur J Pharmacol 712(1-3): 53-59.
83. Chen YY, Li J, Hu JD, Zheng J, Zheng ZH, et al. (2013) [Reversing effects of emodin on multi-drug resistance in resistant HL-60/ADR cells]. Zhongguo Shi Yan Xue Ye Xue Za Zhi 21(6): 1413-1422.

84. Choi RJ, Ngoc TM, Bae K, Cho HJ, Kim DD, et al. (2013) Anti-inflammatory properties of anthraquinones and their relationship with the regulation of P-glycoprotein function and expression. Eur J Pharm Sci 48(1-2): 272281.

85. Min H, Niu M, Zhang W, Yan J, Li J, et al. (2017) Emodin reverses leukemia multi-drug resistance by competitive inhibition and downregulation of P-glycoprotein. PLoS One 12(11): e0187971.

86. Dalrymple JM, Stamp LK, O’Donnell JL, Chapman PT, Zhang M, et al. (2008) Pharmacokinetics of oral methotrexate in patients with rheumatoid arthritis. Arthritis Rheum 58(11): 3299-3308.

87. Bottaro B, Larsen (2008) Fatty acid synthase as a potential therapeutic target in cancer. Bone 23(1): 1-7.

88. Sadowski MC, Pouwer RH, Gunter JH, Lubik AA, Quinn RJ, et al. (2014) The fatty acid synthase inhibitor triclosan: repurposing an anti-microbial agent for targeting prostate cancer. Oncotarget 5(19): 9362-9381.

89. Alzahrani AS (2019) PI3K/Akt/mTOR inhibitors in cancer: At the bench and bedside. Semin Cancer Biol 59: 125-132.

90. Saha SK, Lee SB, Won J, Choi HY, Kim K, et al. (2017) Correlation between Oxidative Stress, Nutrition, and Cancer Initiation. Int J Mol Sci 18(7): 1544 